From the Cancer Epidemiology Unit, Center for Experimental Research and Medical Sciences and Center for Oncologic Prevention Piemonte, University of Turin; Department of Pathology, Molinette Hospital, Turin, Italy; and Clinical Epidemiology Unit, Karolinska Institutet, Stockholm, Sweden.

Submitted May 19, 2008; accepted November 14, 2008; published online ahead of print at www.jco.org on May 26, 2009

Supported in part by the Italian Association for Cancer Research; the Compagnia San Paolo/FIRMS; the Piedmont Region; the Italian Ministry of University; and by the Master in Epidemiology, University of Turin, and San Paolo Foundation (L.V.).

Presented in part at the 98th Annual Meeting of the American Association for Cancer Research, April 14-18, 2007 Los Angeles, CA; and the XXXI Annual Meeting of the Italian Association for Epidemiology, Marina di Ostuni (Brindisi), Italy, October 17-19, 2007

Terms in blue are defined in the glossary, found at the end of this article and online at www.jco.org.

Authors' disclosures of potential conflicts of interest and author contributions are found at the end of this article.

Corresponding author: Lorenzo Richiardi, MD, PhD, Cancer Epidemiology Unit, University of Turin, Via Santena 7. 10126 Turin, Italy; e-mail: Iorenzo richiardi@unito.jt.

The Acknowledgment is included in the full-text version of this article, available online at www.jco.org. It is not included in the PDF version (via Adobe ${ }^{\circledR}$ Reader ${ }^{\circledR}$ ).

(C) 2009 by American Society of Clinical Oncology

0732-183X/09/2719-3161/\$20.00

DOI: 10.1200/JCO.2008.18.2485

\title{
Promoter Methylation in APC, RUNX3, and GSTP1 and Mortality in Prostate Cancer Patients
}

Lorenzo Richiardi, Valentina Fiano, Loredana Vizzini, Laura De Marco, Luisa Delsedime, Olof Akre, Anna Gillio Tos, and Franco Merletti

\section{$\begin{array}{lllllllll}\text { A } & \text { B } & \text { S } & \text { T } & \text { R } & \text { A } & \text { C } & T\end{array}$}

\section{Purpose}

There is a need to better understand prostate cancer progression and identify new prognostic markers for this tumor. We investigated the association between promoter methylation in a priori selected genes and survival in two independent large series of prostate cancer patients.

\section{Methods}

We followed up with two cohorts of patients (216 patients diagnosed in 1982 to 1988 and 243 patients diagnosed in 1993 to 1996) diagnosed at one hospital pathology ward in Turin, Italy. DNA was obtained from paraffin-embedded tumor tissues and evaluated for promoter methylation status in glutathione $S$-transferase (GSTP1), adenomatous polyposis coli (APC), and runt-related transcription factor 3 ( $R \cup N X 3)$.

\section{Results}

The two cohorts had different prevalences of methylation in APC ( $P=.047)$, GSTP1 $(P=.002)$, and RUNX3 $(P<.001)$. Methylation in APC was associated with an increased risk of prostate cancer-specific mortality (hazard ratio $[\mathrm{HR}]=1.42 ; 95 \% \mathrm{Cl}, 0.98$ to 2.07 in the 1980 s cohort; $\mathrm{HR}=1.57 ; 95 \% \mathrm{Cl}, 0.95$ to 2.62 in the 1990 s cohort; $\mathrm{HR}=1.49 ; 95 \% \mathrm{Cl}, 1.11$ to 2.00 in the two cohorts combined). In subgroup analyses, the HRs were higher among patients with a Gleason score less than $8(\mathrm{HR}=1.52 ; 95 \% \mathrm{Cl}, 0.85$ to 2.73 in the 1980 s cohort; $\mathrm{HR}=2.09 ; 95 \% \mathrm{Cl}, 1.02$ to 4.28 in the 1990s cohort). Methylation in RUNX3 was associated with prostate cancer mortality only in the 1990s cohort, and methylation in GSTP1 did not predict mortality in either cohort.

\section{Conclusion}

The pattern of hypermethylation may have changed after the introduction of prostate-specific antigen testing in the beginning of the 1990s. Promoter methylation in APC was identified as a marker for prostate cancer progression.

\section{J Clin Oncol 27:3161-3168. C 2009 by American Society of Clinical Oncology}

\section{INTRODUCTION}

Prostate cancer is the most frequent cancer in the United States and Western Europe. ${ }^{1}$ The incidence has been increasing by approximately $3 \%$ per year during several decades. ${ }^{2}$ The trends shifted in the late 1980s and early 1990s when prostate-specific antigen (PSA) testing became widespread. ${ }^{3}$ In the United States, for example, the annual percent change in incidence was $2.4 \%$ before 1989 and 18.4\% between 1989 and $1992 .{ }^{4}$

The use of PSA testing remains under debate. First, PSA testing has low sensitivity and positive predictive value, implying high proportions of both false-positive and false-negative tests. ${ }^{5,6}$ Second, PSA screening identifies indolent cancers, resulting in overdiagnosis. ${ }^{7}$ Patients diagnosed with localized prostate cancers, notably those detected through PSA, may have an excellent prognosis when left untreated. For these patients, it would be important to distinguish between indolent and aggressive tumors. Several preoperative nomograms developed in the last 10 years have been based on clinicopathologic variables, including PSA, Gleason score, clinical stage, and number of positive and negative biopsy cores. ${ }^{8,9}$ The collective prognostic value of these factors is unsatisfactory, and better understanding of the biology of prostate cancer progression is needed to identify new markers. ${ }^{9,10}$

Emerging evidence indicates that epigenetic alterations, particularly DNA hypermethylation, play a role in human carcinogenesis and tumor progression. ${ }^{11,12}$ Several studies found that presence of $\mathrm{CpG}$ island (clusters of dinucleotides of a cytosine and a guanosine) methylation in the promoter of some cancer-related genes, such as glutathione $S$-transferase (GSTP1), adenomatous polyposis coli (APC), and PTGS2, may be 
used as a diagnostic test to distinguish between normal and prostate cancer tissue. ${ }^{13,14}$ In addition, methylation in single genes and methylation indices have been found to be associated with clinicopathologic indicators of poor prognosis, although there is inconsistency between studies. ${ }^{15-23}$ The association between promoter hypermethylation in prostate cancer and clinical outcome or mortality has been less investigated, and investigation was performed mostly in relatively small patient series with short follow-up using heterogeneous or intermediate outcomes. ${ }^{15,18,24-27}$

We studied the prostate cancer survival in association with promoter methylation in GSTP1, APC, and runt-related transcription factor 3 (RUNX3). GSTP1 is the most frequently investigated gene in prostate cancer epigenetics and has been found to be frequently methylated in prostate tumor tissues in several studies. $A P C$ and RUNX3 were selected among genes (EDNRB, COX2, PTGS2, APC, RASSF1, and RUNX3) for which aberrant methylation status was reported to be associated with clinical features of poor prognosis in prostate cancer patients at the time when our study was designed. ${ }^{28}$ Because they are involved in signaling and transcription pathways, their inhibition by promoter methylation may plausibly have a role in prostate cancer progression. ${ }^{28,29}$ In addition, their polymerase chain reaction (PCR) target sequences were short enough to be successfully investigated by published primers in paraffin-embedded tissues preserved for several years.

Two independent cohorts of, in total, 459 prostate cancer patients were observed for prostate cancer mortality. The first cohort included patients diagnosed in the 1980s, whereas members of the second cohort were diagnosed in the 1990s. The second cohort was used to validate the findings in the first cohort and to study any possible changes in the methylation patterns between the 1980s, before the introduction of PSA testing, and the 1990s, during the PSA era.

\begin{tabular}{|c|c|c|c|c|c|}
\hline Characteristic & No. of Patients & $\%$ & No. of Patients & $\%$ & $P^{*}$ \\
\hline No. of person-years & & & & & \\
\hline \multicolumn{6}{|l|}{ Mortality } \\
\hline Overall & 195 & & 177 & & \\
\hline Missing cause of death & 8 & & 0 & & \\
\hline \multicolumn{6}{|l|}{ Survival time, years } \\
\hline Median & \multicolumn{2}{|c|}{3.1} & \multicolumn{2}{|c|}{6.3} & \\
\hline Range & \multicolumn{2}{|c|}{$0-14$} & \multicolumn{2}{|c|}{$0-14$} & \\
\hline Age, years & & \multirow{2}{*}{\multicolumn{2}{|c|}{70.0}} & .003 \\
\hline Mean & \multicolumn{2}{|c|}{$\begin{array}{r}72.3 \\
7.5\end{array}$} & & & \\
\hline \multicolumn{3}{|l|}{ Source of tumor tissue } & & & $<.001$ \\
\hline Biopsy & 182 & 84.3 & 164 & 67.5 & \\
\hline TURP & 11 & 5.1 & 45 & 18.5 & \\
\hline Radical prostatectomy & 23 & 10.6 & 34 & 14.0 & \\
\hline \multicolumn{3}{|l|}{ Gleason score } & & & $<.001$ \\
\hline$<7$ & 32 & 14.8 & 136 & 56.0 & \\
\hline 7 & 85 & 39.4 & 34 & 14.0 & \\
\hline $8+$ & 99 & 45.8 & 73 & 30.0 & \\
\hline \multicolumn{3}{|l|}{ Methylation in GSTP1 } & & & .002 \\
\hline Yes & 159 & 76.1 & 150 & 62.8 & \\
\hline No & 50 & 23.9 & 89 & 37.2 & \\
\hline Missing & 7 & - & 4 & - & \\
\hline
\end{tabular}




\section{METHODS}

\section{Cohorts}

The cohorts consist of consecutive prostate cancer patients of any age identified at a single pathology ward of the San Giovanni Battista Hospital, the main hospital in the city of Turin (900,000 inhabitants), Italy. The first cohort, hereafter referred to as the 1980 s cohort, includes patients who received a biopsy of the prostate, transurethral resection of the prostate, or radical prostatectomy between 1982 and 1988. Patients in the second cohort, the 1990s cohort, were diagnosed at the hospital between 1993 and 1996. The 1980s and 1990s cohorts included 298 and 280 eligible patients, respectively. The study was approved by the local ethical committee.

Slices of formalin-fixed and paraffin-embedded tumor tissue (PETs) were obtained from each patient. DNA extraction from the PETs was successful in $77 \%(n=228)$ of the patients in the 1980 s cohort and $90 \%(n=253)$ of patients in the 1990s cohort. Patients with successful extraction remained for further analysis.

From each patient's pathology report, we obtained information on name and surname, age, tumor grade, place of residence, and, limited to the 1990s cohort, Gleason score. Three patients in the 1980s cohort and two patients in the 1990s cohort with incorrect demographic information were excluded from the study. Diagnostic slides for patients in the 1980s cohort were traced and re-evaluated by a pathologist (L.D.), who assigned the Gleason score. We could not trace the slides of eight tumors. In those cases, we used the information on tumor grade that was available in the pathology report; well-differentiated tumors were translated to a Gleason score of 6 or less, moderately differentiated tumors corresponded to a score of 7 , and poorly differentiated tumors had a score of $8+$.

\section{Follow-Up}

We observed the patients from the date of the pathology report to February 13, 2006 for the 1980s cohort and to January 15, 2007 for the 1990s cohort. Dead patients were censored on their date of death. Information on vital status and copies of the death certificates came from the demographic offices of Turin and the towns of the hinterland, and we ascertained migration at the Migration Office. Follow-up information was 95\% complete (nine patients lost) for the 1980s cohort and $96 \%$ complete (eight patients lost) for the 1990s cohort. Patients with no follow-up information were excluded from the study. The death certificates for eight patients in the 1980s cohort were not retrievable. These patients were excluded from the analyses focusing on prostate cancer mortality.

\section{Molecular Analyses}

We extracted genomic DNA from 3 to 5 (10- $\mu \mathrm{m}$ thick) sequential sections of PETs and checked for adequacy by PCR amplification of the $\beta$-globin gene. ${ }^{30}$ If a patient had multiple blocks of PET, a block embedding tissue with tumor cells was chosen after histologic review of the corresponding slide. If a patient had both biopsy and prostatectomy blocks, we analyzed the biopsy. For all patients retained in the study, $\beta$-globin PCR analysis resulted in clearly sharp detectable amplicons after gel electrophoresis, allowing adequacy for methylation-specific analyses.

The genomic DNA samples, including positive controls for methylated and unmethylated status, underwent bisulfite modification using CpGenome DNA Modification Kit (Intergen Co, Purchase, NY) following the manufacturer's instructions. ${ }^{31}$ Bisulfite-modified DNA was used as a template for PCR amplification using primers specific for either the methylated or the modified unmethylated DNA. The sets of specific primers and their annealing temperatures for methylated and unmethylated forms of GSTP1, APC, and RUNX3 gene promoters were selected from published sequences. ${ }^{20,32}$ For PCR amplification, $4 \mu \mathrm{L}$ of bisulfite-modified DNA was added in a final volume of $25 \mu \mathrm{L}$ PCR mix containing $1 \mathrm{X}$ PCR buffer (15 $\mathrm{mmol} / \mathrm{L}$ Tris, $\mathrm{pH}$ 8.0; $50 \mathrm{mmol} / \mathrm{L} \mathrm{KCl}$; and $6.7 \mathrm{mmol} / \mathrm{L} \mathrm{MgCl}_{2}$ ), deoxynucleotide triphosphates $(2 \mathrm{mmol} / \mathrm{L}$ each $)$, primers $(0.4 \mu \mathrm{mol} / \mathrm{L}$ each per reaction $)$, and 1.25 U of AmpliTaq Gold DNA polymerase (Applied Biosystems, Foster City, CA). PCR conditions were as follows: 10 minutes at $95^{\circ} \mathrm{C}, 30$ seconds at $95^{\circ} \mathrm{C}, 1$ minute at primer-specific annealing temperature, 1 minute at $72^{\circ} \mathrm{C}$ for 45 cycles, and 7 minutes at $72^{\circ} \mathrm{C} .{ }^{20,32}$ All PCR amplifications were performed in a Gene Amp PCR System 9700 Thermal Cycler (Applied Biosystems). Bisulfite-modified CpGenome universal methylated DNA (Intergen Co) was used as positive control for methylated alleles, and bisulfite-modified DNA from normal human lymphocytes was used as a positive control for unmethylated alleles. Negative PCR controls without DNA were included in each PCR run. Ten microliters of each PCR amplification were loaded onto $2 \%$ agarose gel stained with ethidium bromide and visualized by ultraviolet transillumination. As shown in previous studies, this method has high sensitivity, detecting one methylated nucleotide in 1,000 unmethylated nucleotides. ${ }^{33}$

\section{Statistical Analyses}

We compared clinical and pathologic characteristics of the patients in the 1980s cohort and the 1990s cohort using univariate $\chi^{2}$ and $t$ tests. ${ }^{34}$ Variables were classified as reported in Table 1. No information on PSA variables, tumor stage, and number of positive and negative biopsies was available in the pathology reports.

Through logistic regression, we estimated, separately for the 1980s and 1990s cohorts, the prevalence odds ratios for the association between methylation in the genes and clinical and pathologic characteristics. ${ }^{35}$ Patients with missing methylation status in one gene were excluded from the corresponding analyses.

For the older cohort, we ended follow-up after 14 years to apply the same maximum follow-up for both cohorts. The effect of methylation status in each of the three genes on cumulative mortality from prostate cancer was investigated taking into account competing risks, ${ }^{36}$ and differences in overall prostate

\begin{tabular}{|c|c|c|c|c|c|c|c|c|c|}
\hline \multirow[b]{2}{*}{$\begin{array}{l}\text { Gleason } \\
\text { Score }\end{array}$} & \multicolumn{3}{|c|}{ GSTP1 } & \multicolumn{3}{|c|}{$A P C$} & \multicolumn{3}{|c|}{$R \cup N X 3$} \\
\hline & $\begin{array}{l}\text { Prevalence of } \\
\text { Methylation (\%) }\end{array}$ & POR* & $95 \% \mathrm{Cl}$ & $\begin{array}{l}\text { Prevalence of } \\
\text { Methylation (\%) }\end{array}$ & POR* & $95 \% \mathrm{Cl}$ & $\begin{array}{l}\text { Prevalence of } \\
\text { Methylation (\%) }\end{array}$ & POR* & $95 \% \mathrm{Cl}$ \\
\hline \multicolumn{10}{|c|}{ 1980s cohort } \\
\hline$<7$ & 65.5 & 1 & - & 25.8 & 1 & - & 89.3 & 1 & - \\
\hline 7 & 82.1 & 2.27 & 0.81 to 6.34 & 40.5 & 1.66 & 0.64 to 4.31 & 81.0 & 0.40 & 0.10 to 1.70 \\
\hline $8+$ & 74.0 & 1.18 & 0.45 to 3.13 & 35.1 & 1.25 & 0.48 to 3.25 & 86.2 & 0.58 & 0.13 to 2.53 \\
\hline \multicolumn{10}{|l|}{ 1990s cohort } \\
\hline$<7$ & 57.0 & 1 & - & 38.5 & 1 & - & 44.7 & 1 & - \\
\hline 7 & 62.5 & 1.21 & 0.53 to 2.77 & 48.5 & 1.39 & 0.63 to 3.08 & 48.4 & 1.21 & 0.53 to 2.76 \\
\hline $8+$ & 73.6 & 2.02 & 1.06 to 3.84 & 55.6 & 2.07 & 1.13 to 3.81 & 53.6 & 1.36 & 0.73 to 2.52 \\
\hline
\end{tabular}

Abbreviation: POR, prevalence odds ratio.

*POR adjusted for age, source of tumor tissue, year of tissue collection, and residence. 
cancer mortality were evaluated with the Gray's test. ${ }^{37}$ Using age as the temporal axis, we used Cox proportional hazards regression models to estimate hazard ratios (HRs) with $95 \%$ CIs of prostate cancer mortality by methylation status and Gleason score (two categories: $<8$ and $\geq 8$ ). Patients were censored at death from causes other than prostate cancer. Both a graphical check and formal tests based on Schoenfeld residuals $(P>.15)$ indicated that the proportional hazard assumption was met. We included the following covariates in the models: source of tumor tissue, Gleason score, and follow-up duration (time-dependent variable in three categories: $<1$ year, between 1 and 3 years, and $3+$ years). Inclusion of place of residence in the models did not affect HR estimates. HRs specific for categories of follow-up duration were estimated introducing terms for the interaction between this variable and methylation status.

We also investigated the interaction between Gleason score and methylation in APC and RUNX3. In exploratory analyses, we further studied the association between survival and number of methylated genes. Patients with missing methylation status in at least one of the genes were excluded from this analysis ( $\mathrm{n}=53,12 \%$ of the patients).

To understand whether a lack of cancer cells in some tissue slices biased our estimates, we provisionally restricted survival analyses to patients positive for methylation in GSTP1, for whom tumor cells were most likely sufficiently represented, and patients who underwent biopsy, where all available tissue was paraffin embedded in one single block.

\section{RESULTS}

Patients in the 1990s cohorts were younger and had twice the median survival time than those in the 1980s cohort (Table 1). In the 1990s cohort, tumor tissue was obtained from transurethral resections of the prostate and radical prostatectomies more often than in the 1980 s cohort.

\section{Prevalence of Promoter Methylation}

In the 1980s cohort, the prevalence of methylation in $A P C$ was lower $(P=.047)$ but methylation in GSTP1 $(P=.002)$ and RUNX3 $(P<.001)$ was more frequent compared with the 1990s cohort. These differences remained after adjustment for Gleason score, age, and source of the tumor tissue.

Methylation in GSTP1 and APC was positively associated with Gleason score only in the 1990s cohort (Table 2). Age, source of tumor tissue, and year of tissue collection were not associated with methylation (data not shown). In both cohorts, pair-wise comparisons revealed that methylation in each gene was independent from methylation in the other two genes $(P>.25)$.

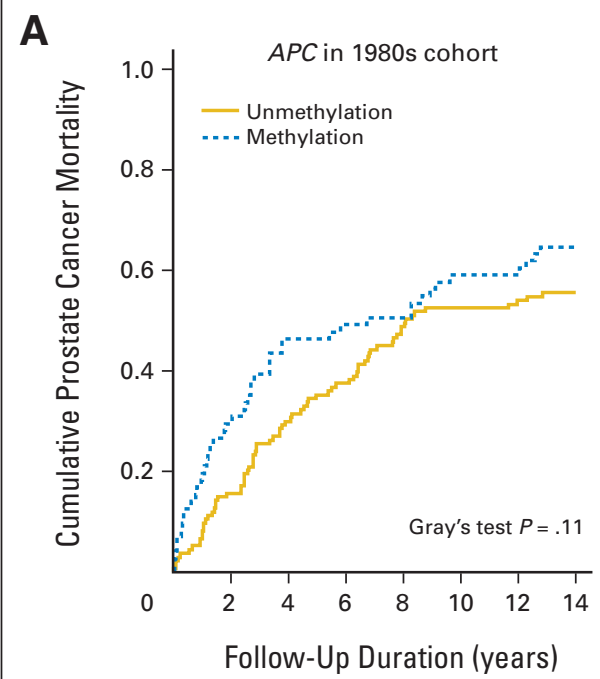

B

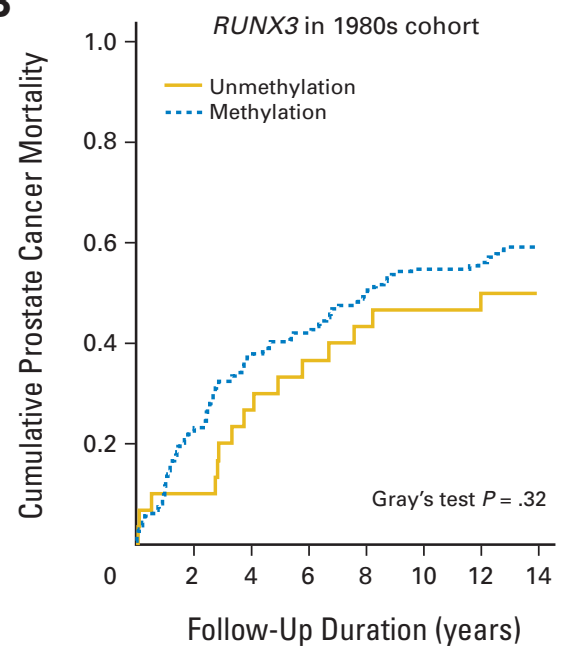

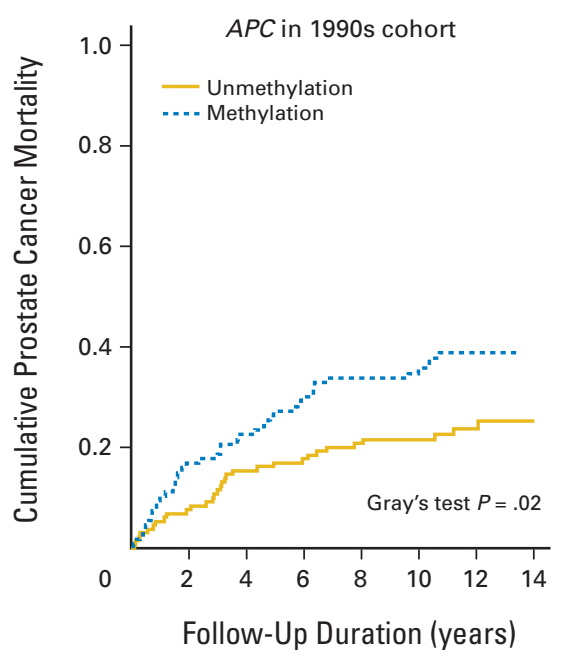

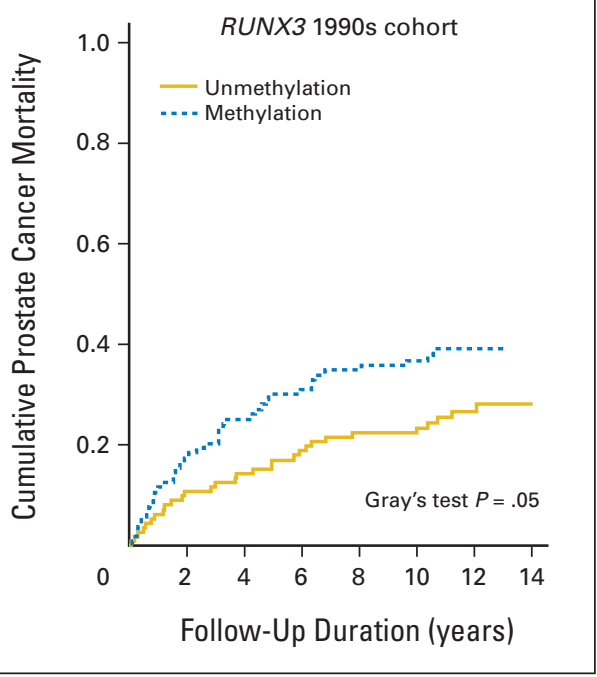

Fig 1. Cumulative prostate cancer mortality by methylation status in (A) APC and (B) RUNX3 in the 1980s cohort and 1990s cohort. 


\section{Promoter Methylation and Tumor Progression}

Patients with methylation in APC had a higher prostate cancer mortality than patients with an unmethylated cancer (Fig 1A). This association was statistically significant only in the 1990s cohort $(P=.02)$. Methylation in RUNX3 was associated with survival in the 1990s cohort $(P=.05)$ but not in the 1980s cohort (Fig 1B). Methylation in GSTP1 was not associated with survival (data not shown).

The HR of prostate cancer mortality for methylation in APC was 1.42 (95\% CI, 0.98 to 2.07) in the 1980s cohort and 1.57 (95\% $\mathrm{CI}, 0.95$ to 2.62 ) in the $1990 \mathrm{~s}$ cohort $(\mathrm{HR}=1.49 ; 95 \% \mathrm{CI}, 1.11$ to 2.00 for the two cohorts combined; Table 3). In the 1990s cohort, the adjusted HR estimate was lower than the crude one, mainly because of the introduction of Gleason score into the model. In the 1980s cohort, the association between methylation in APC and mortality was stronger and statistically significant in the first year of follow-up, whereas in the 1990s cohort, the HR estimate increased with duration of follow-up.

Results were not consistent between the two cohorts for methylation in RUNX3, which was associated with prostate cancer mortality in the 1990s cohort (HR $=1.56 ; 95 \%$ CI, 0.95 to 2.56 ) but not in the 1980s cohort (Table 3). Methylation in GSTP1 was not associated with prostate cancer mortality. Restriction of the analyses to patients who underwent biopsy or were positive for GSTP1 methylation did not substantially change increased HR estimates for methylation in APC and RUNX3 (data not shown).

The effect of methylation in APC or RUNX3 at different levels of Gleason score is summarized in Table 4. In the 1980s cohort, Gleason score had a small impact on the HR estimates, whereas in the 1990s cohort, we found a doubled HR from prostate cancer mortality among patients with a Gleason score less than 8 both for methylation in APC ( $\mathrm{HR}=2.09 ; 95 \% \mathrm{CI}, 1.02$ to 4.28$)$ and in RUNX3 (HR $=2.40 ; 95 \% \mathrm{CI}, 1.18$ to 4.91 ). In the two cohorts combined, the HR of prostate cancer mortality increased with increasing number of methylated genes $(P=.002$ for linear trend; Table 5).

\section{DISCUSSION}

We found that methylation in $A P C$ is associated with prostate cancer mortality, particularly among those with a highly to moderately differentiated tumor. A similar association was found for methylation in RUNX3 in the 1990s cohort, whereas methylation in GSTP1 was not associated with risk. The results also indicated a shift in the methylation patterns from the 1980s to the 1990s.

Table 3. Prostate Cancer Mortality for Methylation in GSTP1, APC, and RUNX3 by Duration of Follow-Up in 1980s and 1990s Cohorts

\begin{tabular}{|c|c|c|c|c|c|c|c|c|c|c|}
\hline $\begin{array}{l}\text { Methylation and Gleason } \\
\text { Score }\end{array}$ & No. of Deaths & \multicolumn{3}{|c|}{ Overall 14-Year Follow-Up } & \multicolumn{2}{|c|}{$<1$ Year } & \multicolumn{2}{|c|}{ 1-3 Years } & \multicolumn{2}{|c|}{$3+$ Years } \\
\hline \multicolumn{11}{|l|}{ 1980s cohort } \\
\hline \multicolumn{11}{|l|}{ Methylation in GSTP1 } \\
\hline \multicolumn{11}{|l|}{ Methylation in APC } \\
\hline No & 74 & 1 & 1 & & 1 & & 1 & & 1 & \\
\hline Yes & 46 & $1.46 \dagger$ & 1.42 & 0.98 to 2.07 & 2.66 & 1.12 to 6.31 & 1.41 & 0.72 to 2.75 & 1.10 & 0.63 to 1.93 \\
\hline \multicolumn{11}{|l|}{ Methylation in $R U N X 3$} \\
\hline No & 15 & 1 & 1 & & 1 & & 1 & & 1 & \\
\hline Yes & 97 & 1.32 & 1.22 & 0.70 to 2.14 & 0.97 & 0.27 to 3.43 & 2.39 & 0.72 to 7.89 & 0.93 & 0.45 to 1.94 \\
\hline \multicolumn{11}{|l|}{ Methylation in GSTP1 } \\
\hline No & 17 & 1 & 1 & & 1 & & 1 & & 1 & \\
\hline Yes & 58 & $2.02 \dagger$ & 1.44 & 0.82 to 2.54 & 1.62 & 0.52 to 5.04 & 0.94 & 0.34 to 2.62 & 1.74 & 0.75 to 4.04 \\
\hline \multicolumn{11}{|l|}{ Methylation in $A P C$} \\
\hline No & 31 & 1 & 1 & & 1 & & 1 & & 1 & \\
\hline Yes & 41 & $1.99+$ & 1.57 & 0.95 to 2.62 & 1.48 & 0.55 to 3.96 & 1.15 & 0.42 to 3.16 & 1.86 & 0.93 to 3.72 \\
\hline \multicolumn{11}{|l|}{ Methylation in RUNX3 } \\
\hline No & 30 & 1 & 1 & & 1 & & 1 & & 1 & \\
\hline Yes & 40 & 1.74 & 1.56 & 0.95 to 2.56 & 1.58 & 0.60 to 4.14 & 1.33 & 0.48 to 3.68 & 1.66 & 0.85 to 3.27 \\
\hline \multicolumn{11}{|l|}{ Gleason score } \\
\hline$<8$ & 36 & 1 & 1 & & 1 & & 1 & & 1 & \\
\hline $8+$ & 36 & $3.50 t$ & 3.27 & 2.00 to 5.37 & 6.50 & 2.08 to 20.3 & 3.61 & 1.31 to 9.94 & 2.34 & 1.16 to 4.73 \\
\hline
\end{tabular}




\begin{tabular}{|c|c|c|c|c|c|c|}
\hline \multirow[b]{2}{*}{ Methylation } & \multicolumn{3}{|c|}{ Gleason $<8$} & \multicolumn{3}{|c|}{ Gleason 8+ } \\
\hline & No. of Deaths & $\mathrm{HR}^{*}$ & $95 \% \mathrm{Cl}$ & No. of Deaths & $\mathrm{HR}^{*}$ & $95 \% \mathrm{Cl}$ \\
\hline \multicolumn{7}{|c|}{ 1980s cohort } \\
\hline \multicolumn{7}{|c|}{ Methylation in APC } \\
\hline No & 30 & 1 & & 44 & 1 & \\
\hline Yes & 20 & 1.52 & 0.85 to 2.73 & 26 & 1.36 & 0.81 to 2.26 \\
\hline \multicolumn{7}{|c|}{ Methylation in RUNX3 } \\
\hline No & 6 & 1 & & 9 & 1 & \\
\hline Yes & 38 & 1.14 & 0.45 to 2.88 & 59 & 1.09 & 0.52 to 2.29 \\
\hline \multicolumn{7}{|l|}{ 1990s cohort } \\
\hline \multicolumn{7}{|c|}{ Methylation in $A P C$} \\
\hline No & 16 & 1 & & 15 & 1 & \\
\hline Yes & 20 & 2.09 & 1.02 to 4.28 & 21 & 1.07 & 0.51 to 2.26 \\
\hline \multicolumn{7}{|c|}{ Methylation in $R \cup N X 3$} \\
\hline No & 14 & 1 & & 16 & 1 & \\
\hline Yes & 21 & 2.40 & 1.18 to 4.91 & 19 & 0.84 & 0.38 to 1.85 \\
\hline
\end{tabular}

Gene-specific prevalences of methylation were different between the two cohorts. These differences are unlikely a result of selection of patients or laboratory heterogeneities for the following reasons: the same methodologies for molecular analyses were used in the two cohorts; within each cohort, the lack of association of the year of tissue collection with prevalence of methylation suggests that tissue preservation did not affect the results; both cohorts included an unselected series of patients, and the catchment area of the hospital did not change over time; and in the 1990s cohort, a higher number of patients received radical prostatectomy, but the differences between the two cohorts remained in the comparison restricted to patients who underwent biopsy.

The decrease in age at diagnosis and increase in survival that we observed in the 1990s cohort is consistent with an effect of opportunistic PSA screening. ${ }^{7}$ It has been estimated that, each year, more than $10 \%$ of men older than 50 years received a PSA test at the end of the 1990s in Northern Italy. ${ }^{38,39}$ Therefore, one plausible explanation for the observed difference in methylation prevalences between the 1980s cohort and the 1990s cohort could be that PSA-detected prostate cancers are characterized by a different methylation pattern. This could be explained either by a larger proportion of early tumors or a greater proportion of indolent cancers in the 1990s cohort. Distinguishing between these two mechanisms cannot be done with our data, but it would help in the understanding of

\begin{tabular}{|c|c|c|c|}
\hline No. of Methylated Genes & No. of Deaths & $\mathrm{HR}^{*}$ & $95 \% \mathrm{Cl}$ \\
\hline 0 & 5 & 0.80 & 0.31 to 2.08 \\
\hline 1 & 32 & 1.00 & \\
\hline 2 & 94 & 1.53 & 1.02 to 2.30 \\
\hline 3 & 44 & 1.97 & 1.24 to 3.15 \\
\hline
\end{tabular}

Abbreviation: HR, hazard ratio.

*HR was adjusted for follow-up duration, Gleason score, source of tumor tissue, and cohort. $P=.002$ for trend. the biology of prostate cancer and possibly in the identification of new prognostic markers.

The methylation prevalences that we found are in accordance with previous data. Prevalence of GSTP1 methylation has been estimated to be greater than $60 \%$, with large heterogeneities between studies. ${ }^{13,28,40}$ The two largest studies conducted so far found prevalences of $73 \%$ in 179 patients ${ }^{22}$ and $66 \%$ in 291 patients. ${ }^{19}$ Most of the studies that investigated methylation in APC in prostate cancer found a prevalence of greater than $50 \% .^{14,15,17,20,22,24,26,28,41-44}$ Little is known about the prevalence of methylation in RUNX3 from previous studies. $^{20,22}$

Our data suggest that methylation in APC may be involved in prostate cancer progression. Even if we lacked information on some important variables, such as PSA and TNM stage, residual confounding is unlikely to be a major limitation. First, we adjusted for Gleason score, which is a strong prognostic variable. Second, studies evaluating the correlation between methylation in APC and clinicopathologic variables found heterogeneous results, with most of the association estimates being weak. ${ }^{14,17,22,43}$ The confounding potential of these variables after adjustment for Gleason score should thus be limited.

To date, little is known about the role of epigenetics and promoter methylation in prostate cancer progression. Our results on APC are predated by similar findings from two recent smaller studies. In a cohort of 74 prostate cancer patients who underwent prostatectomy, approximately $70 \%$ of the patients experienced PSA reoccurrence, metastasis, or death, with an HR for promoter methylation in APC of 3.0 (95\% CI, 1.4 to 6.3$).{ }^{24}$ A three-fold statistically significantly increased HR has also been reported by Henrique et al, ${ }^{26}$ who investigated 83 prostate cancer patients, of whom 15 died from prostate cancer during follow-up.

The APC complex is known from studies of colorectal cancer cells to function as a gatekeeper in the cell, preventing the transcription of gene products that promote cell proliferation and survival rather than differentiation and apoptosis. ${ }^{45}$ Hypermethylation of APC implies silencing of this gatekeeper, making the cell vulnerable to further 
epigenetic and genetic changes and, thus, progression toward the development of invasive cancer. This is consistent with our finding of a decreasing survival with number of methylated genes, which further supports a role of gene hypermethylation in cancer progression. We also found that hypermethylation of $A P C$ is associated with survival among patients with tumors of high to moderate differentiation but not among those with a poorly differentiated tumor. This finding may suggest that changes in APC might occur early in the tumorigenesis in the prostate, making the cell vulnerable to further changes, but in tumors with poor differentiation, changes in APC add little to the malignant potential.

In this large survival analysis of two independent series of unselected prostate cancer patients, we found that hypermethylation in the promoter of the APC gene is involved in prostate cancer progression. The possibility of using this as a prognostic marker will have to be addressed in future independent cohorts with more detailed clinical information available. When comparing patients from the 1980s, before the introduction of PSA testing, with those from the 1990s, after the introduction of PSA, we found a considerable change in the methylation pattern, possibly indicating different biologic behavior of PSA-detected and other prostate cancers.

\section{AUTHORS' DISCLOSURES OF POTENTIAL CONFLICTS} OF INTEREST

The author(s) indicated no potential conflicts of interest.

\section{AUTHOR CONTRIBUTIONS}

Conception and design: Lorenzo Richiardi, Anna Gillio Tos,

Franco Merletti

Financial support: Lorenzo Richiardi, Franco Merletti

Provision of study materials or patients: Valentina Fiano,

Laura De Marco, Luisa Delsedime

Collection and assembly of data: Valentina Fiano, Laura De Marco,

Luisa Delsedime

Data analysis and interpretation: Lorenzo Richiardi, Valentina Fiano,

Loredana Vizzini, Laura De Marco, Luisa Delsedime, Olof Akre,

Anna Gillio Tos, Franco Merletti

Manuscript writing: Lorenzo Richiardi, Loredana Vizzini, Olof Akre,

Anna Gillio Tos, Franco Merletti

Final approval of manuscript: Lorenzo Richiardi, Valentina Fiano, Loredana Vizzini, Laura De Marco, Luisa Delsedime, Olof Akre, Anna Gillio Tos, Franco Merletti

\section{REFERENCES}

1. Ferlay J, Bray F, Pisani $P$, et al: GLOBOCAN 2000: Cancer Incidence, Mortality and Prevalence Worldwide, Version 1.0. IARC CancerBase No. 5. Lyon, France, IARC Press, 2001

2. Zaridze DG, Boyle P, Smans M: International trends in prostatic cancer. Int J Cancer 33:223-230, 1984

3. Kvåle R, Auvinen A, Adami $\mathrm{HO}$, et al: Interpreting trends in prostate cancer incidence and mortality in the five Nordic countries. J Natl Cancer Inst 99:1881-1887, 2007

4. Hankey BF, Feuer EJ, Clegg LX, et al: Cancer surveillance series: Interpreting trends in prostate cancer-part I: Evidence of the effects of screening in recent prostate cancer incidence, mortality, and survival rates. J Natl Cancer Inst 91:1017-1024, 1999

5. Thompson IM, Ankerst DP, Chi $C$, et al: Operating characteristics of prostate-specific antigen in men with an initial PSA level of $3.0 \mathrm{ng} / \mathrm{mL}$ or lower. JAMA 294:66-70, 2005

6. Hernández J, Thompson IM: Prostate-specific antigen: A review of the validation of the most commonly used cancer biomarker. Cancer 101:894904, 2004

7. Draisma G, Boer R, Otto SJ, et al: Lead times and overdetection due to prostate-specific antigen screening: Estimates from the European Randomized Study of Screening for Prostate Cancer. J Natl Cancer Inst 95:868-878, 2003

8. Stephenson AJ, Scardino PT, Eastham JA, et al: Preoperative nomogram predicting the 10-year probability of prostate cancer recurrence after radical prostatectomy. J Natl Cancer Inst 98:715-717, 2006

9. Chun FK, Karakiewicz PI, Huland $\mathrm{H}$, et al: Role of nomograms for prostate cancer in 2007. World J Urol 25:131-142, 2007

10. Fall K, Garmo H, Andren O, et al: Prostatespecific antigen levels as a predictor of lethal prostate cancer. J Natl Cancer Inst 99:526-532, 2007
11. Esteller M: Cancer epigenomics: DNA methylomes and histone-modification maps. Nat Rev Genet 8:286-298, 2007

12. Jones PA, Baylin SB: The epigenomics of cancer. Cell 128:683-692, 2007

13. Perry AS, Foley R, Woodson $K$, et al: The emerging roles of DNA methylation in the clinical management of prostate cancer. Endocr Relat Cancer 13:357-377, 2006

14. Bastian PJ, Ellinger J, Wellmann $A$, et al: Diagnostic and prognostic information in prostate cancer with the help of a small set of hypermethylated gene loci. Clin Cancer Res 11:4097-4106, 2005

15. Yegnasubramanian S, Kowalski J, Gonzalgo $M L$, et al: Hypermethylation of $\mathrm{CpG}$ islands in primary and metastatic human prostate cancer. Cancer Res 64:1975-1986, 2004

16. Reibenwein J, Pils D, Horak P, et al: Promoter hypermethylation of GSTP1, AR, and 14-3-3sigma in serum of prostate cancer patients and its clinical relevance. Prostate 67:427-432, 2007

17. Jerónimo C, Henrique R, Hoque MO, et al: A quantitative promoter methylation profile of prostate cancer. Clin Cancer Res 10:8472-8478, 2004

18. Bastian PJ, Palapattu GS, Lin $X$, et al: Preoperative serum DNA GSTP1 CpG island hypermethylation and the risk of early prostate-specific antigen recurrence following radical prostatectomy. Clin Cancer Res 11:4037-4043, 2005

19. Enokida H, Shiina H, Urakami S, et al: Ethnic group-related differences in $\mathrm{CpG}$ hypermethylation of the GSTP1 gene promoter among AfricanAmerican, Caucasian and Asian patients with prostate cancer. Int J Cancer 116:174-181, 2005

20. Kang GH, Lee S, Lee HJ, et al: Aberrant CpG island hypermethylation of multiple genes in prostate cancer and prostatic intraepithelial neoplasia. J Pathol 202:233-240, 2004

21. Enokida H, Shiina H, Urakami S, et al: Smoking influences aberrant $\mathrm{CpG}$ hypermethylation of multiple genes in human prostate carcinoma. Cancer 106:79-86, 2006

22. Cho NY, Kim BH, Choi M, et al: Hypermethylation of $\mathrm{CpG}$ island loci and hypomethylation of
LINE-1 and Alu repeats in prostate adenocarcinoma and their relationship to clinicopathological features. J Pathol 211:269-277, 2007

23. Padar A, Sathyanarayana UG, Suzuki M, et al: Inactivation of cyclin D2 gene in prostate cancers by aberrant promoter methylation. Clin Cancer Res 9:4730-4734, 2003

24. Rosenbaum E, Hoque MO, Cohen $Y$, et al: Promoter hypermethylation as an independent prognostic factor for relapse in patients with prostate cancer following radical prostatectomy. Clin Cancer Res 11:8321-8325, 2005

25. Cottrell $S$, Jung $K$, Kristiansen $G$, et al: Discovery and validation of 3 novel DNA methylation markers of prostate cancer prognosis. J Urol 177:1753-1758, 2007

26. Henrique R, Ribeiro FR, Fonseca D, et al: High promoter methylation levels of APC predict poor prognosis in sextant biopsies from prostate cancer patients. Clin Cancer Res 13:6122-6129, 2007

27. Ellinger $J$, Bastian $P J$, Jurgan $T$, et al: $C p G$ island hypermethylation at multiple gene sites in diagnosis and prognosis of prostate cancer. Urology 71:161-167, 2008

28. Bastian PJ, Yegnasubramanian $S$, Palapattu GS, et al: Molecular biomarker in prostate cancer: The role of $\mathrm{CpG}$ island hypermethylation. Eur Urol 46:698-708, 2004

29. Verras M, Sun Z: Roles and regulation of Wnt signaling and beta-catenin in prostate cancer. Cancer Lett 237:22-32, 2006

30. Gillio-Tos A, De Marco L, Fiano $V$, et al: Efficient DNA extraction from 25-year-old paraffinembedded tissues: Study of 365 samples. Pathology 39:345-348, 2007

31. Dikshit RP, Gillio-Tos A, Brennan $P$, et al: Hypermethylation, risk factors, clinical characteristics, and survival in 235 patients with laryngeal and hypopharyngeal cancers. Cancer 110:1745-1751, 2007

32. Tsuchiya T, Tamura G, Sato K, et al: Distinct methylation patterns of two APC gene promoters in normal and cancerous gastric epithelia. Oncogene 19:3642-3646, 2000 
33. Esteller $\mathrm{M}$ : $\mathrm{CpG}$ island hypermethylation and tumor suppressor genes: A booming present, a brighter future. Oncogene 21:5427-5440, 2002

34. Armitage P, Berry G, Matthews JNS: Statistical Methods in Medical Research (ed 4). Oxford, United Kingdom, Blackwell Science, 2002

35. Breslow NE, Day NE: Statistical Methods in Cancer Research. Volume I: The Analysis of CaseControl Studies. IARC Scientific Publication No. 32. Lyon, France, IARC Press, 1980

36. Kalbfleisch JD, Prentice RL: The Statistical Analysis of Failure Time Data. New York, NY, John Wiley, 1980

37. Gray RJ: A class of K-sample tests for comparing the cumulative incidence of a competing risk. Ann Stat 16:1141-1154, 1988
38. Russo A, Autelitano M, Bellini $A$, et al: Estimate of population coverage with the prostate specific antigen (PSA) test to screen for prostate cancer in a metropolitan area of northern Italy. J Med Screen 9:179-180, 2002

39. D'Ambrosio G, Samani F, Cancian M, et al: Practice of opportunistic prostate-specific antigen screening in Italy: Data from the Health Search database. Eur J Cancer Prev 13:383-386, 2004

40. Meiers I, Shanks JH, Bostwick DG: Glutathione S-transferase pi (GSTP1) hypermethylation in prostate cancer: Review 2007. Pathology 39:299304, 2007

41. Bastian PJ, Ellinger J, Heukamp LC, et al: Prognostic value of $\mathrm{CpG}$ island hypermethylation at PTGS2, RAR-beta, EDNRB, and other gene loci in patients undergoing radical prostatectomy. Eur Urol 51:665-674, 2007

42. Tokumaru $Y$, Harden SV, Sun DI, et al: Optimal use of a panel of methylation markers with GSTP1 hypermethylation in the diagnosis of prostate adenocarcinoma. Clin Cancer Res 10:5518-5522, 2004

43. Maruyama R, Toyooka S, Toyooka $\mathrm{KO}$, et al: Aberrant promoter methylation profile of prostate cancers and its relationship to clinicopathological features. Clin Cancer Res 8:514-519, 2002

44. Enokida $H$, Shiina $H$, Urakami S, et al: Multigene methylation analysis for detection and staging of prostate cancer. Clin Cancer Res 11:6582-6588, 2005

45. Baylin SB, Ohm JE: Epigenetic gene silencing in cancer: A mechanism for early oncogenic pathway addiction? Nat Rev Cancer 6:107-116, 2006

\begin{tabular}{|c|c|}
\hline \multicolumn{2}{|c|}{ Glossary Terms } \\
\hline $\begin{array}{l}\text { Promoter hypermethylation: Methylation of the pro- } \\
\text { moter region of a gene can lead to DNA silencing as a conse- } \\
\text { quence of the inability of activating transcriptional factors to } \\
\text { bind to the promoter region, a process important in gene tran- } \\
\text { scription. In addition, repressor complexes may be attracted to } \\
\text { sites of promoter methylation, leading to the formation of inac- } \\
\text { tive chromatin structures. }\end{array}$ & $\begin{array}{l}\text { PSA (prostate-specific antigen): A protein produced by cells of } \\
\text { the prostate gland, the blood level of PSA is used as a tumor marker for } \\
\text { men who may be suspected of having prostate cancer. Most physicians } \\
\text { consider } 0 \text { to } 4.0 \mathrm{ng} / \mathrm{mL} \text { as the normal range. Levels of } 4 \text { to } 10 \text { and } 10 \text { to } \\
20 \mathrm{ng} / \mathrm{mL} \text { are considered slightly and moderately elevated, respectively. } \\
\text { PSA levels have to be complemented with other tests to make a firm } \\
\text { diagnosis of prostate cancer. }\end{array}$ \\
\hline $\begin{array}{l}\mathrm{CpG} \text { island: DNA sequences with a high density of CpGs are } \\
\text { termed CpG islands. CpG islands are typically unmethylated in } \\
\text { normal tissues but often become methylated in tumors. The pat- } \\
\text { terns of hypermethylated CpG islands vary according to the his- } \\
\text { tologic origin of the tumor. }\end{array}$ & $\begin{array}{l}\text { APC (adenomatous polyptosis coli) gene: A tumor suppres- } \\
\text { sor gene. Mutations in the gene are responsible for familial adenoma- } \\
\text { tous polyposis (germline mutations) or sporadic (somatic mutations) } \\
\text { colorectal tumors. The gene product is known to interact with adherens } \\
\text { junction proteins, a- and b-catenins, suggesting a role in cell adhesion. }\end{array}$ \\
\hline \multirow{2}{*}{$\begin{array}{l}\text { Epigenetic: The transfer of information from one cell to its } \\
\text { descendants without the information's being encoded in the nu- } \\
\text { cleotide sequence of the DNA. The methylation of the promoter } \\
\text { to inactivate a gene is an example of an epigenetic change. Epige- } \\
\text { netic inheritance is typically transmitted in dividing cells. Al- } \\
\text { though rare, it is occasionally seen in traits being transmitted } \\
\text { from one generation to another. Epigenetic variants can arise } \\
\text { spontaneously and just as spontaneously revert. }\end{array}$} & $\begin{array}{l}\text { Cox proportional hazards regression model: The Cox pro- } \\
\text { portional hazards regression model is a statistical model for regression } \\
\text { analysis of censored survival data. It examines the relationship of cen- } \\
\text { sored survival distribution to one or more covariates. It produces a } \\
\text { baseline survival curve, covariate coefficient estimates with their stan- } \\
\text { dard errors, risk ratios, } 95 \% \text { CIs, and significance levels. }\end{array}$ \\
\hline & $\begin{array}{l}\text { PCR (polymerase chain reaction): PCR is a method that al- } \\
\text { lows logarithmic amplification of short DNA sequences within a } \\
\text { longer DNA molecule. }\end{array}$ \\
\hline
\end{tabular}

